\title{
LA PALABRA COMO IMAGEN CÍVICA: \\ EL USO DE ACRÓNIMOS Y SIGLAS TOPONÍMICAS \\ EN LAS ACUÑACIONES PROVINCIALES DE HISPANIA
}

\author{
THE WORD AS A CIVIC IMAGE: USE OF ACRONYMS AND TOPONYMIC INITIALS IN REGIONAL \\ MINTS OF HISPANIA
}

\author{
ALBERTO AGUILERA HERNÁNDEZ \\ Centro de Estudios Borjanos \\ Institución «Fernando el Católico» \\ albertoaguileraher@yahoo.es \\ http://orcid.org/0000-0002-3288-3923
}

Recepción: 02-10-2016

Aceptación: 21-02-2017

\section{Resumen}

En el artículo se estudia el papel que las siglas y tipos epigráficos acrónimos desempeñaron en la moneda cívica hispana desde el Segundo Triunvirato hasta el reinado de Calígula, tanto como elementos secundarios que complementan a una composición iconográfica, como en su condición de tipos principales en determinadas cecas.

Palabras clave. Numismática; iconografía; epigrafía; acuñaciones cívicas; Hispania; topónimos; siglas; acrónimos; Segundo Triunvirato; dinastía Julio-Claudia.

\begin{abstract}
This article studies the role played by epigraphic initials and types in the civic coinage of Hispania from the Second Triumvirate until the reign of Caligula, both as secondary elements complementing an iconographic composition, and as the main types of specific mints.
\end{abstract}

Key words. Numismatics; iconography; epigraphy; civic coinage; Hispania; toponyms; initials; acronyms; Second Triumvirate; Julio-Claudian dynasty. 


\section{INTRODUCCIÓN}

A menudo, los numísmatas hemos desatendido el estudio de las siglas y tipos epigráficos acrónimos en el marco de los programas cívico-propagandísticos de las cecas provinciales hispanas. Titulaturas, magistraturas locales o el debatido permiso imperial han generado una copiosa literatura científica frente a estas referencias toponímicas concebidas como elementos secundarios que, al margen de referir el lugar de acuñación, complementan a una composición iconográfica principal. En efecto, como ha señalado recientemente Cebrián Sánchez (2013: 126) para el caso de Colonia Augusta Emerita, el uso de topónimos fue uno de los fenómenos más antiguos vinculados al origen y difusión de la moneda que comprobamos en todos los ámbitos culturales de la península ibérica aunque, a su modo de ver, estas fórmulas epigráficas carecen de la significación que caracteriza a las imágenes que conforman el repertorio de la ceca, en contra de lo argumentado por Beltrán Lloris (2002: 179) para Colonia Caesar Augusta, pues entiende que su empleo reiterado las eleva a la condición de tipos emblemáticos del taller al mismo nivel que las restantes composiciones.

Es este el enfoque con el que nos sentimos más identificados, dado que una cosa era dejar constancia epigráfica del centro emisor y otra muy distinta que adquiriese una autonomía plena, bien con su nominación completa o mediante el uso de siglas, acrónimos o abreviaturas, términos que en la mayor parte de las ocasiones se confunden. Así es, el Diccionario de la Real Academia Española (web) define sigla como la «abreviación gráfica formada por el conjunto de letras iniciales de una expresión compleja", mientras que el acrónimo es la «sigla cuya configuración permite su pronunciación como una palabra» o el "vocablo formado por la unión de elementos de dos o más palabras, constituido por el principio de la primera y el final de la última». Por su parte, una abreviatura es la «representación gráfica reducida de una palabra o de un grupo de palabras, obtenida mediante un procedimiento de abreviación en que se suprimen letras finales o centrales, cerrada generalmente con punto y raramente con barra». De ello se deduce que todos los acrónimos pueden ser considerados siglas, aunque no todas las siglas adquieren la condición de acrónimos.

Sobre este particular, de nuevo Cebrián Sánchez (2013: 126) ha indicado que este hábito epigráfico, que engloba con el término general de "acrónimo», solo se documenta en cecas establecidas en colonias de la Tarraconense -Acci, Ilici, Carthago Noua, Tarraco y Caesar Augusta - con la salvedad de Augusta Emerita en Lusitania siendo, por lo tanto, un fenómeno desconocido en la Bética sobre el soporte monetal ${ }^{1}$.

1. No así en el epigráfico, pues las iniciales C C A A se constatan en Colonia Caesarina Augusta Asido; la fórmula C R para Hispalis, bajo la forma sufijada Colonia Romulense y,
Ignoramos los motivos que guiaron al autor para descartar a otros talleres que también recurrieron a fórmulas similares, como la colonia Lepida-Celsa o el municipio de Calagurris, aunque su incorporación no viene a modificar las conclusiones a las que llegó, salvo en el uso limitado a las colonias que, a pesar de ser ciertamente mayoritario, no fue exclusivo (Fig. 1).

En la justificación de su utilización pudieron confluir variadas causalidades, entre las que sin duda se encontró la de facilitar a los usuarios el reconocimiento de su moneda cívica -tema sobre el que volveremos más adelante- pero también la influencia de la cecas estatales, que siguieron incluyendo el acrónimo S P Q R como máxima divisa institucional y, de forma especial, el taller de Roma, que mantuvo la referencia abreviada al decreto senatorial como una tradición formal más que real. Un testimonio que ilustra a la perfección esta dependencia con los modelos imperiales podemos localizarlo en la tercera emisión ilicitana de época de Tiberio, a nombre de los duunviros M. Iulius Settal y L. Sestius Celer (RPC I 196-197), que ofrece como tipo principal de los reversos de los ases y semis un altar consagrado a la Salus Augusta junto a las iniciales C I I A a ambos lados, composición que tomó como referente inmediato el altar representado en

en el caso de Ucubi, las iniciales C(olonia) C(laritas) I(ulia), aunque solo la segunda emitió moneda provincial. Para este y otros casos remitimos a los estudios de Sabio González (2011: 150-163; 2014: 254-255). En lo que concierne a la ausencia de acrónimos y siglas toponímicas en la numismática de la Bética, dicha característica viene a sumarse a las abundantes diferencias que, desde el periodo republicano, caracterizaron las políticas monetarias de las provincias $\mathrm{Ul}$ terior y Citerior, para las que se dista todavía de lograr argumentaciones del todo concluyentes (Ripollès, 2014: 69-70). Además, el que la actividad de la mayor parte de sus talleres no tuviera continuidad en el tiempo, batiendo con frecuencia una sola emisión, bien con Augusto en casos como los de Irippo ( $R P C$ I 55-56), Osset ( $R P C$ I 58-59) y Colonia Patricia (RPC I 127-130), o con Tiberio, tal y como sucede en Colonia Romula (RPC I 73-76) y, posiblemente, también en Abdera (RPC I 124-126), no contribuye a clarificar el problema al presentarnos una instantánea muy puntual del fenómeno y no un proceso continuado que, con más o menos dificultades, sí es posible perfilar en cecas que prolongaron sus emisiones mucho más en el tiempo. Por otra parte, ni tan siquiera parece existir un patrón más o menos común en estas cecas a la hora de decantarse por una fórmula toponímica ni por el lugar que debía ocupar en la moneda. Así, en la emisión augustea de Italica la localizamos en los anversos de los ases (RPC I 60-61) y en los reversos de los semis y cuadrantes (RPC I 62-63), comportamiento idéntico al que aplicó Romula en fechas tan avanzadas como el gobierno de Tiberio (RPC I 73-76). Gades no incluyó jamás ninguna referencia de este tipo y Abdera optó porque fuera en neopúnico (RPC I 124), llegando a convivir con el topónimo latinizado ( $R P C$ I $125)$, que fue el que, finalmente, se mantuvo en una serie de ases (RPC I 126). Tampoco nosotros tenemos una respuesta definitiva que explique estas ausencias en la Bética, aunque a lo largo de estas líneas ofrecemos una serie de reflexiones que pueden contribuir a clarificar este particular en un futuro. 


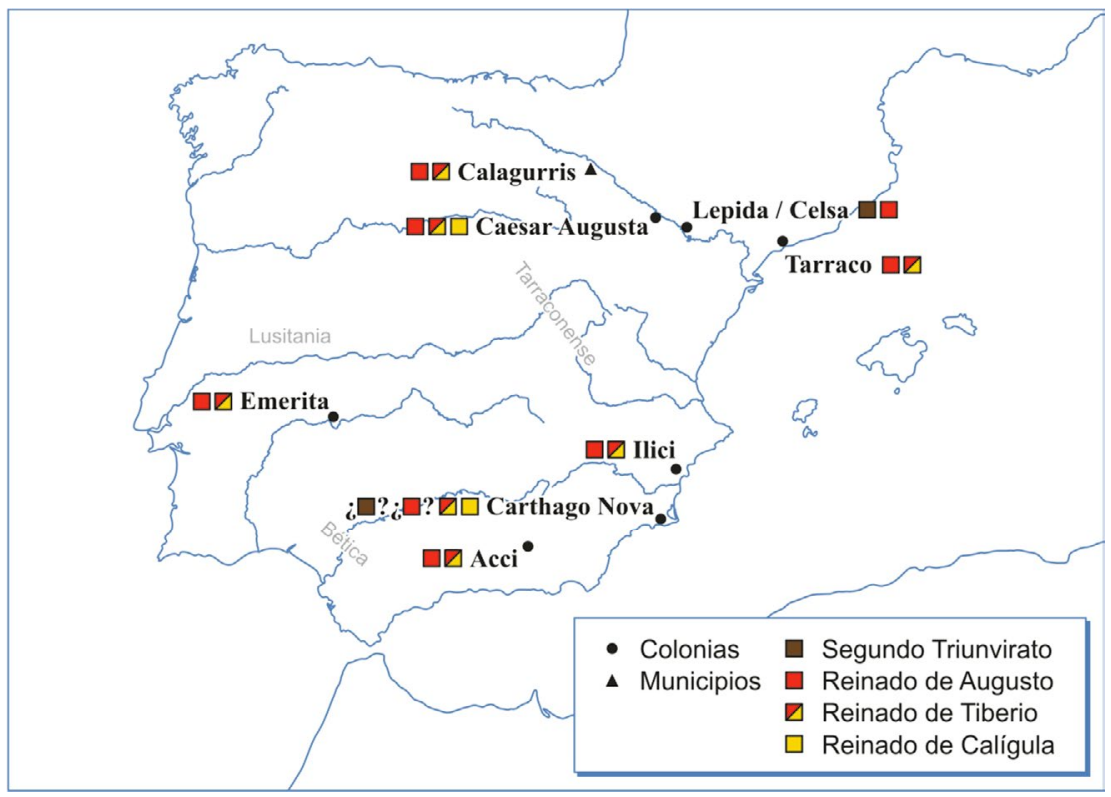

Figura 1: Cecas hispanas que recurrieron al uso epigráfico de acrónimos y siglas toponímicas. (Elaboración propia).

unos bronces romanos bajo el lema de la Providencia y que se ubica entre los caracteres $\mathrm{S} \mathrm{C}\left(R I C \mathrm{I}^{2} 81\right)$. El cambio epigráfico, por lo tanto, obedeció a un evidente y necesario proceso de redefinición del diseño imperial a los parámetros culturales que resultaban propios a la comunidad cívica que lo asumía como emblema característico, lo que se comprueba de igual modo en los bronces que Caesar Augusta dedicó en época de Calígula al Diuus Augustus (RPC I 376 y 383), Germánico ( $R P C I 377$ y 384) y Agripina la Mayor ( $R P C$ I 380 y 385 ), cuando adoptó los retratos que aparecían sobre la moneda estatal contemporánea pero añadiendo la referencia toponímica local $\mathrm{C} \mathrm{C} \mathrm{A}$, a veces en el mismo lugar en el que los respectivos prototipos alojaban la mención a la autorización senatorial ${ }^{2}$.

$\mathrm{Y}$ es que la función de este conjunto de acrónimos y siglas en las cecas hispanas parece moverse en dos ámbitos distintos: por un lado la de complementar a las imágenes locales de los reversos -aunque tampoco faltan ejemplos tempranos en los que se localizó en los anversos, junto al retrato de divinidades o emperadores- y, por otro, su consideración como un tipo cívico más en la misma condición que los restantes que integraron los elencos iconográficos de los respectivos talleres. Con relación a ello, una de las características principales que puede asignarse a estas leyendas es que son un tipo de escritura «expuesta» según la terminología acuñada por Susini (1966) desde un enfoque netamente epigráfico. Asimismo, su dimensión comunicacional también ha sido valorada en numerosas ocasiones por autores como Donati (2002), epigrafista que aun reconociendo que las monedas ejercieron en la Antigüedad una función propagandística similar

2. Sobre este comportamiento en la ceca de Caesar Augusta, dirigimos a: Aguilera Hernández (2015: 827-846). a la de las inscripciones, la realizaron más por la carga semántica de sus imágenes que por el contenido de las leyendas. Esta afirmación, a pesar de resultar válida en su planteamiento, creemos que debe matizarse, al menos en todos los casos en los que los acrónimos o siglas presiden la cara de la moneda en calidad de emblema ciudadano, una disposición que, a todas luces, no tuvo por objeto principal reflejar únicamente al centro emisor y con él, posiblemente, al senado local en su papel de autoridad emisora (Ripollès Alegre, 2010: 17).

Por otro lado, si partimos de la premisa de que todo epígrafe se vio condicionado por el soporte que lo iba a contener y la función que se le quiso conceder, resulta tentador ligar su utilización a un intento por optimizar al máximo el siempre pequeño campo monetal ${ }^{3}$. Sin embargo, a nada que profundizamos en los testimonios hispanos nos percatamos de que este comportamiento debe interpretarse en una dirección bien distinta a la planteada. Valga como muestra el revelador caso de Caesar Augusta, colonia que en sus primeros años de actividad monetaria referenció su denominación oficial de manera desarrollada y continua hasta que la séptima emisión ( $R P C$ I 325-329), que documenta la magistratura honorífica de Germánico hacia

3. Velázquez Soriano (2008: 7-41) ofrece interesantes reflexiones en torno al concepto de epigrafía, cuestiones de método de estudio y su relación con otras ciencias, entre las que se encuentra la numismática, así como a la facilidad de interpretación de las abreviaturas por el efecto óptico que provocaban en el lector una vez estandarizadas aunque su origen, si bien es cierto, pudo encontrarse en la necesidad de aprovechamiento del soporte.

4. Debemos hacer notar que los cuadrantes (RPC I S2-I-329A) adscritos a esta emisión no incluyen referencia toponímica alguna. 
el año 7 d.C., consagró el uso exclusivo de la grafía separada mediante las iniciales C C A que, sin excepción alguna, figuraron en todos los valores emitidos desde entonces hasta la clausura del taller. En opinión de Beltrán Lloris (2014: 131-139), el que las escasas inscripciones locales corroboren este rasgo distintivo, debe conectarse con la particularidad de que la ciudad fuera la única fundación de todo el Imperio en ostentar en su onomástica oficial el nombre casi completo de Augusto, por lo que el empleo de la sigla contribuía a subrayar de forma inequívoca la identidad de los nombres, tanto el de la ciudad como el de su fundador.

La concepción y perpetuación en el tiempo de siglas y acrónimos, como demuestra el ejemplo anterior, no se produjo por una necesidad de aprovechamiento del soporte, sino que fue el resultado y la expresión político-administrativa de una determinada identidad y cultura cívica, de tal manera que las realidades ideológicas-culturales, propias y específicas de cada uno de los centros emisores que optaron por estas fórmulas epigráficas, no solo resultó determinante a la hora de su asunción, sino también en la de su permanencia o exclusión, o bien en la función que se les quiso atribuir. Así pues, en la caracterización de ese trasfondo cultural que generó las leyendas -pero para el que también se crearon- participaron numerosos agentes y factores, no siempre fáciles de concretar, y que obligan a interrogarse sobre si fue compartido entre los responsables de las emisiones y los destinatarios primarios de las mismas. La cuestión, junto con algunos de los argumentos onomásticos y toponímicos desgranados en el párrafo antecedente, nos conduce directamente a la posible oposición entre la toponimia oficial e imperial de las ciudades que facilitan las siglas y acrónimos, y su auténtica trascendencia e impacto en la oralidad de las gentes, tema planteado con acierto por Sabio González (2011: 145-190; 2014: 249-265). Si como ha comprobado este autor, el uso de los cognomina de las ciudades fue testimonial fuera de los vehículos oficiales de propaganda ${ }^{5}$, estos epígrafes deberían interpretarse como parte fundamental en los programas propagandísticos locales, diseñados desde la voluntad política de sus élites y al servicio de sus intereses en el marco de la ideología imperial.

Por estas razones, no consideramos probable que la mímesis jugara un papel destacado en este tema, aunque sí resulta obligado tener en consideración los posibles vínculos entre los talleres y que, en el día de hoy, quedan patentes de muy diversas formas, ya sea a través de la documentación del estilo artístico de un mismo equipo de artesanos itinerantes, como se documenta en Celsa, Carthago Noua e Ilici (Llorens

5. Otro tanto podemos decir sobre la perduración de las nomenclaturas oficiales de las ciudades. De entre los 54 casos estudiados por Sabio González (2011: 187-190; 2014: 264265), solo Caesar Augusta ha llegado hasta la actualidad con el topónimo vivo de Zaragoza.
Forcada, 1994: 81), o bien con la producción híbrida en Calagurris y Celsa (Ripollès Alegre, 2010: 19) entre otros. En cambio, en el nacimiento y consolidación de este hábito epigráfico pudieron ejercer una mayor influencia los veteranos legionarios deducidos por $\mathrm{Au}-$ gusto $^{6}$, ya que no puede ser visto como un hecho casual que Augusta Emerita (RPCI 16 y 18), Acci (RPC I 133-134), Ilici (RPC I 189-191) y Caesar Augusta (RPCI 325-326) aplicaran por primera vez en su historia monetaria siglas o acrónimos junto a diversos signa militaria y a las menciones epigráficas a sus legiones fundadoras. Previamente, la misma Lepida (RPC I 261) los relacionó con el busto de la Victoria, que rememoraba el éxito militar de César (Hurtado Mullor, 2013: 135), y Carthago Noua (RPC I 174-178) a una cuadriga con uexillum que Llorens Forcada (1994: 71) interpreta como alusión a un triunfo militar. De igual modo, esta tendencia se comprueba en las restantes provincias del Imperio, aunque el hecho de que no tengamos constancia de la existencia de trabajos que aborden el fenómeno específicamente obliga a tomar los resultados con prudencia. De cualquier forma, un primer acercamiento a la numismática provincial parece corroborar que el empleo de este tipo de leyendas, sin resultar excesivamente generalizado, gozó de mayor arraigo en las colonias de la zona oriental del Imperio ${ }^{7}$ que, como las hispanas, fueron el fruto de la política municipalizadora y de fundación o refundación de ciudades que Augusto llevó a cabo, frente a un

6. En este sentido, cabe interrogarse sobre el papel que los antiguos legionarios, ya como licenciados, ejercieron en la vida política de los centros urbanos donde se asentaron. Las argumentaciones de Saquete Chamizo (2010: 81) se dirigen hacia esta dirección, pero Palao Vicente (2010: 194-195), aunque ve posible que los antiguos mandos militares se integraran dentro de los grupos dirigentes de las comunidades civiles, opina que debieron de ser muy poco frecuentes, siendo las circunstancias particulares de los individuos y los requisitos exigidos por cada una de las ciudades en el acceso a las magistraturas las que determinarían la participación activa de los veteranos en la vida pública. Según este último autor, la pérdida de determinados derechos que comportaba el ejercicio de las magistraturas, como los munera publica, pudo ser uno de estos factores en contra de la integración.

7. Sin ánimo de ser exhaustivos, destacamos que, por la reiteración en el uso, las cecas que sobresalen en Acaya fueron Colonia Augusta Achaica Patrensis con el rótulo C A A P y Colonia Iulia Augusta Dumaeorum con la fórmula C I A D, que compartió con Colonia Iulia Augusta Dyrrhachium en Macedonia, provincia en la que también se localiza Colonia Victrix Philippensium, en cuyas monedas se grabaron las iniciales C V P. Asimismo, tenemos algunos casos representativos en Bitinia y Ponto con Colonia Iulia Concordia Apamea, que optó por los epígrafes C I C o C I C A, y Colonia Iulia Felix Sinope, que hizo lo propio con C F I o C I F. Finalmente, citamos a Colonia Gemella (o Gemina) Iulia Pariana y Colonia Gemella (o Gemina) Iulia Lampsacus, ambas en Asia, que recurrieron a los letreros C G I P y C G I $\mathrm{L}$ respectivamente. 
uso más testimonial en el ámbito occidental ${ }^{8}$ donde, sin embargo, sí destacaron las acuñaciones cívicas de Hispania como vamos a analizar a continuación.

\section{SIGLAS Y ACRÓNIMOS EN LAS ACUÑA- CIONES HISPANAS: MODALIDADES Y TEN- DENCIAS DEL SEGUNDO TRIUNVIRATO AL PRINCIPADO}

El primer uso de una sigla en las acuñaciones cívicas hispanas pudo recaer en Colonia Victrix Iulia Lepida en época triunviral, ceca que ha sido objeto de estudio por parte de Hurtado Mullor (2013). Hasta el cambio de topónimo documentado en la séptima emisión ${ }^{9}$, las fórmulas epigráficas utilizadas fueron dos: la leyenda abreviada COL(onia) VIC(trix) IVL(ia) LEP(ida) o la sigla C V I L. Ambas se encuentran en el anverso de los ases (RPC I 261) rubricados por M. Ful. y C. Otac., $p r$. quin. junto a la cabeza de Victoria con palma sobre su hombro, mientras que para el reverso se optó por la escena fundacional de un colono guiando la yunta de bueyes con la mención epigráfica de los magistra$\operatorname{dos}^{10}$. Desde entonces, si tomamos como referencia el ordenamiento de las emisiones propuesto por Hurtado Mullor (2013: 110-111), se dio una alternancia entre ambas leyendas $^{11}$. Así, en la tercera, a cargo de C. Balbus y L. Porcius, pr. IIuir (RPC I 262), se mantuvo la sigla en el anverso de los ases junto al busto de Victoria (Fig. 2), y también en los semis (RPC I 265) de la quinta emisión, bajo la responsabilidad de los ediles $L$. Semp. Max. y M. Caec., en relación con la cabeza de Hércules con clava ( $R P C$ I 265). Su última aparición se comprueba en las emisiones VIa y VIc, de nuevo sobre el anverso de los valores fraccionarios que aluden a $L$. Calp. y Sex. Nig. como ediles, bien en dependencia

8. Tras las provincias hispanas, la mayor representatividad en el occidente del Imperio parece recaer en África Proconsular. Colonia Iulia Concordia Karthago recurrió en época de Tiberio a las iniciales C I C; Colonia Iulia Pia Paterna hizo lo propio con el acrónimo C I P y el municipium de Utica con M V. Mucha menos importancia cobra la Galia, aunque contamos con Colonia Iulia Viennensis y el uso del epígrafe C I V como ejemplo.

9. La fundación de la colonia se debió a Marco Emilio Lépido pero existen discrepancias en cuanto a su cronología. Para algunos autores debe situarse en el año 44 a.C., mientras que otros la adscriben al 48-47, meses después de la batalla de Ilerda, con el fin de asentar a 6.000 galos y veteranos legionarios. De cualquier forma, la caída en desgracia de Lépido en el 36 a.C. supuso que la ciudad cambiara su nombre a $\mathrm{Co}$ lonia Iulia Victrix Celsa, latinizando el nombre del antiguo oppidum de kelse. Sobre el tema y las distintas propuestas fundacionales véase García-Bellido (2003: 273-290).

10. Sobre este tipo de representaciones fundacionales remitimos a Aguilera Hernández (2014: 95-129; 2015: 335-372).

11. Debe tenerse en cuenta que, para este autor, la emisión de L. Nep. y L. Sura, pr. IIuir (RPC I 263) es anterior a la de $C$. Balbo y L. Porcio, pr. IIuir (RPC I 262).
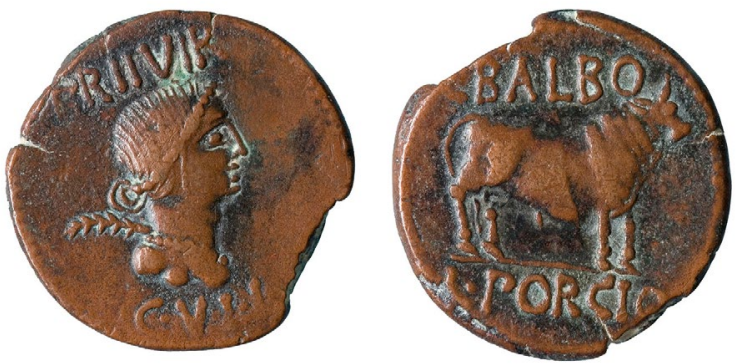

Figura 2: As (RPC I 262) de Lepida a nombre de C. Balbo y L. Porcio con el epígrafe C V I L en el anverso, 44-36 a.C. (MNAC/GNC 044747. Tomado de: Domínguez y Aguilera, 2012: 77).

con la cabeza frontal del sol en los semis ( $R P C$ I 266) o con un jabalí en los cuadrantes ( $R P C$ I 268).

Una de las novedades más importantes en la historia monetaria de esta ceca tuvo lugar con los duumuiri L. Pompe. Bucco y L. Corne. Fronto en torno al 27 a.C. (RPC I 269), cuando se incorporó el retrato de Octaviano en el anverso y se modificó la onomástica oficial de la ciudad por la mención abreviada COL V I CELSA, que siguió localizada en esta cara de la moneda hasta la serie controlada hacia el 13 a.C. por $L$. Sura y L. Bucco (RPC I 271), cuando pasó al reverso. Durante todo el gobierno de Augusto fue esta la leyenda por la que se optó, con distintas formas abreviadas y siempre complementando a las imágenes. Solo en el reverso de unos cuadrantes batidos entre el 11-5/3 a.C. por los ediles L. Aufid. Pansa y Sex. Pomp. Nigro (RPC I 277) se escogió la sigla C V I como tipo epigráfico sin incluir ninguna mención al topónimo Celsa ${ }^{12}$.

El siguiente taller en recurrir a un elemento epigráfico de estas características pudo ser el de $\mathrm{Acci}^{13}$ con anterioridad al 13 a.C. Sobre el anverso de los ases, y en ambas caras de los semis de la primera emisión (RPC I 133-134), encontramos el letrero C(olonia) I(ulia) G(emella) $A C$ (ci) ubicado entre los espacios centrales de las insignias legionarias, mientras que la variante C I G ACCI se muestra sobre estos mismos valores ( $R P C$ I 135-136) en la última emisión labrada hacia el 12 a.C., acompañando a los signa militaria o al apex y simpulum respectivamente. En lo que afecta a Ilici, cuya ceca fue objeto de trabajo hace algunos años por Llorens Forcada (1987), con posterioridad

12. En realidad, tanto los semis y cuadrantes acuñados por $L$. Baggio y Mn. Festo IIuir, como los semis de L. Aufid. Pansa y Sex. Pomp. Nigro aed, no contienen representaciones iconográficas en el reverso. En el primer valor ocupa el centro del campo la leyenda C V I CELS; en el segundo C V I CEL y, en el tercero, C V I CELSA. Por ello, los cuadrantes que comentamos deben ser entendidos como una prolongación de esta tendencia, pero con la particularidad de no incluir abreviaturas ni menciones al topónimo Celsa.

13. A falta de un estudio actualizado de la ceca remitimos a la visión de conjunto que ofrece Chaves Tristán (1976: 141-158). 
al 15 a.C. batió semis (RPC I 189-191) a nombre de los duumuiri L. Manlio y T. Petronio con la mención C(olonia) C Il(ici) A(ugusta) en el reverso y en relación a símbolos militares, pero que modificó por C(olonia) I(ulia) Il(ici) A(ugusta $)^{14}$ en la siguiente, en el 13-12 a.C., a expensas de los duumuiri quinquenales $Q$. Papirius Carus y $Q$. Terentius Montanus (RPC I 192-193), ubicándose entre las columnas de un templo tetrástilo con el rótulo IVNONI en el arquitrabe.

En Tarraco, la utilización de la sigla C(olonia) $V$ (rbs) T(riumphalis) (Tarraco) se constata en el monetario acuñado entre el 2 a.C. y el 2 d.C. Su función desde la primera emisión fue doble: por un lado complementar a las imágenes principales en los reversos de ases (RPC I 210), pero también actuó en los cuadrantes ( $R P C$ I 214) como tipo independiente en el interior de una láurea (Fig. 3) a la par que los semis (RPC I 211-213) confirman el uso de la modalidad C V T TAR(R). En estas dos líneas, la sigla C V T fue utilizada en la siguiente emisión, posterior al 4 d.C., bien como elemento secundario en los reversos de los ases ( $R P C$ I 215) y en los anversos de los cuadrantes ( $R P C$ I 217), en conexión al retrato de Tiberio o a un toro respectivamente, o como tipo propio en los reversos de estos últimos y en los de los semis (RPC I 216), en ambos casos en el interior de una láurea.

En Augusta Emerita, cuyo taller cuenta con la monografía de Cebrián Sánchez (2013), el acrónimo C(olonia) A(ugusta) E(merita) surgió en semis y cuadrantes posteriores al 2 a.C. (RPC I 16, 18-19), ya sea junto a un aquila entre dos signa o a la pátera, lituus y jarra respectivamente, corroborando por primera vez su condición jurídica hasta entonces omitida. Ello llevó a Canto (1989: 164) a establecer un nuevo

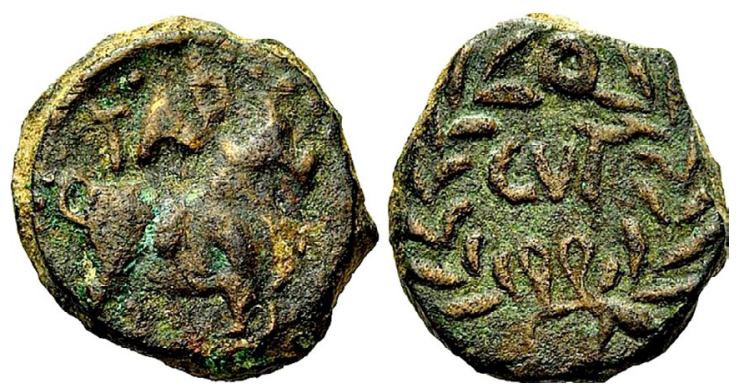

Figura 3: Cuadrante (RPC I 214) de Tarraco con las siglas C $\mathrm{V} T$ en el reverso dentro de una láurea, post. 2 a.C. (Jesús Vico S.A. Auction 131, 9 October 2012, lot. 608, de la ex-colección Cervera. Ex HSA-24541. Recuperado de: https://www.numisbids.com)

14. Como recoge Amela Valverde (2013: 125, nota. $n^{\circ}$ 1), se desconoce el significado de la abreviatura $C$ de la primera denominación, habiéndose propuesto Caesariana, Caesarea, Caesariensis, Coloni, Coloniae, Concordia o Contributa, ninguna de ellas concluyente, aunque dichas siglas parecen confirmar una primera colonización cesariana seguida de un nuevo asentamiento con Augusto. proceso fundacional con no demasiada aceptación por la comunidad científica al considerar que la ciudad no fue una creación augustea, sino que vino a sustituir a un praesidium militar cesariano ${ }^{15}$. No obstante, las diferencias con otras cecas, como Caesar Augusta o Tarraco, son notorias, porque frente a la homogeneidad de estas, en el taller emeritense se evidencia la alternancia de variados formatos toponímicos, dentro incluso de la misma emisión que comentamos: AVGVSTA EMERITA en los dupondios, ases, semis y cuadrantes ( $R P C$ I 12-13, 17; RPC I S2-I-18A; $R P C$ I S3-I-18A), y AV EM ( $R P C$ I 14) o EME(R) ( $R P C$ I 15) en distintas series de semis. En cualquier caso, todos ellos actuaron como elementos epigráficos secundarios vinculados a las composiciones de los reversos, a excepción de una serie de cuadrantes (RPC I S2-I$18 \mathrm{~A})$, en los que se concibió como tipo principal del reverso dentro de una corona.

Por su parte, la ceca de Calagurris, cuyo estudio se debe a Ruiz Trapero (1968), fue la única ubicada en un municipio que añadió la sigla $M$ (unicipium) C(alagurris) I(ulia) a partir de la emisión de M. Lic. Capel. y C. Ful. Rutil. (RPC I 444), del 2 a.C., pues hasta entonces las fórmulas toponímicas basadas en distintas formas abreviadas habían sido variadas: CALAGVRRI IVLIA NASSICA en la primera y segunda emisión ( $R P C$ I 431 y 432); MVN CAL IVL en la tercera ( $R P C$ I 433$)$, cuarta ( $R P C$ I 434$)$ y quinta ( $R P C$ I 435); MVN CAL con distintos nexos de la sexta a la novena ( $R P C$ I 436, 437, 438, 439), junto con los semis y cuadrantes de la décima (RPC I 442-443); MVN CAL(AG) también en la novena ( $R P C$ I 440) y $\underline{M V}$ CAL IVLIA en los ases de la décima ( $R P C$ I 441). La emisión undécima no supuso únicamente el nacimiento de la nueva modalidad epigráfica que comentamos, sino que inauguró la tendencia de ubicar las leyendas toponímicas en el reverso. Pero si esta nueva ubicación sentó precedentes no podemos decir lo mismo de la perpetuación de la sigla, y para las siguientes series de Augusto, salvo en las unidades acuñadas por $L$. Valentinus y L. Nouus (RPC I 445-446), se optó por otro tipo de leyendas.

Las acuñaciones de Carthago Noua, de las que disponemos del trabajo realizado por Llorens Forcada (1994), constatan su denominación como Vrbs Iulia Noua Karthago/Carthago de diversos modos a lo largo de su historia monetaria: C V I N; V(R) I N K; C V I N C; (C) V I N K y V I N C. La primera ocasión la localizamos en la emisión anónima situada tradicionalmente en época pre-augustea (RPC I 151; Llorens Forcada, 1994: 49-50), aunque no faltan propuestas que la circunscriben a comienzos del reinado de

15. La autora hizo la afirmación discutible que su nominación de colonia solo apareció en el monetario tiberiano, lo que llegó a admitir también Cebrián Sánchez (2008: 248). 
Tiberio $^{16}$ mientras que, para la siguiente, tenemos que esperar a las no menos problemáticas series de semis y cuadrantes a nombre de los quinquenales $P$. Turullio y M. Postumius Albinus (RPC I 174-178) fechadas por Llorens Forcada (1994: 70) en el gobierno de Tiberio, bien en el 17-18 d.C. o en el 23-24 d.C., y por otros en el de Augusto. El consenso sobre la cronología de ambas dista de ser unánime, pero para lo que a este estudio se refiere interesa destacar que las siglas siempre se grabaron en los reversos como complemento a las imágenes cívicas.

Finalmente, a tenor de la cronología que manejamos, Caesar Augusta ${ }^{17}$ fue la última ceca en incluir la sigla C(olonia) C(aesar) A(ugusta) durante el principado de Augusto. Lo hizo en su octava emisión (RPC I 325-329; $R P C$ I S2-329A), y hasta entonces la referencia toponímica se había realizado con distintas variantes de grafías y nexos de letras en función de los valores y emisiones, lo que produjo una multiplicidad importante de fórmulas (Gómez Barreiro, 2008: 97). Además, en esta emisión concurren numerosas particularidades dignas de tener en cuenta. En primer lugar documenta el desempeño de una magistratura honorífica por parte de Germánico; por segunda vez en su historia monetaria se acuñaron dupondios sobre los que se grabó la yunta fundacional y el uexillum entre signa con menciones a las legiones fundadoras, y también se diseñaron nuevas imágenes cívicas como la del toro mitrado. Todo ello, junto con el nacimiento del tipo epigráfico que, como en Emerita, supone la primera mención a la condición jurídica de la ceca, condujeron a Gómez Pantoja (1994: 169-202) a proponer que la promoción se debió a Germánico en torno al 11 d.C. Por su parte, Gómez Barreiro (2003: 291-307) confirió a la emisión un carácter conmemorativo fundacional, bien del vigésimo o vigésimo quinto aniversario, fechándola en el 5 o 10 d.C. al considerar que la fundación se produjo en el 15 d.C., mientras que en nuestra opinión se debe adscribir hacia el 7 d.C. al defender que la creación de la colonia se pudo producir en el 1918 a.C. a instancias de Agripa (Aguilera Hernández, 2014: 114-120; 2015: 37, 63-72, 186, 258-259).

Sea como fuere, la función del tipo epigráfico se concibió en una doble vertiente: como elemento adicional a las diversas composiciones iconográficas de

16. Las distintas propuestas cronológicas en Llorens Forcada (1994: 49-50). Una de las aportaciones más recientes sobre esta problemática es la de Abascal Palazón (2002: 21-44) que insiste en que el primer uso sistemático del nombre oficial de la ciudad apareció en la emisión ( $R P C$ I 151), que debería situarse a comienzos de la época tiberiana, delante de (RPC I 174-178), ante la dificultad que supone explicar la desaparición del nombre de la colonia en las emisiones que distan entre la fecha tradicional de (RPC 151$)$ y la de $P$. Turullio y M. Postumius Albinus (RPC I 174-178).

17. El estudio exhaustivo de los repertorios iconográficos empleados en la ceca de Caesar Augusta ha sido objeto de nuestra reciente tesis doctoral: Aguilera Hernández (2015).

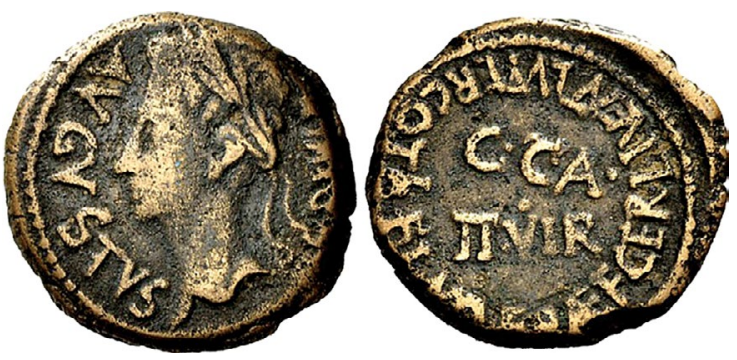

Figura 4: Semis (RPC I 329) de Caesar Augusta, correspondiente a la magistratura honorífica de Germánico, con el epígrafe C C A como tipo principal del reverso, c. 7 d.C. (Jesús Vico S.A. Auction 132, 14 November 2012, lot. 517, de la ex-colección Cervera. Ex HSA-11971. Recuperado de: https:/ www.numisbids.com)

los reversos de los valores de la emisión, salvo en los cuadrantes - que no contienen ninguna leyenda toponímica- y en los semis, donde actúa como emblema independiente siguiendo el modelo de Tarraco (Fig. 4). Este cambio de denominación sentó precedentes, y en la última emisión augustea reapareció con estas mismas funciones junto al retrato de Augusto, que ocupa el anverso de los semis ( $R P C$ I 330-331), pero con plena autonomía y enmarcado por una corona de roble en el reverso de los cuadrantes ( $R P C$ I 332). A partir de entonces ya no hubo marcha atrás, y su uso monopolizó por completo todas las emisiones de la ceca.

\section{LA DIGNIFICACIÓN DE SIGLAS Y ACRÓNI- MOS EN EL REINADO DE TIBERIO}

Durante el gobierno de Tiberio se comprueban en Caesar Augusta dos tendencias en cuanto al uso de la sigla, con un punto de inflexión a partir de la emisión acuñada por M. Catus y L. Vettiacus (RPC I 345-351) en el 31-32 d.C., en un posible contexto conmemorativo del cincuentenario de la fundación (Aguilera Hernández, 2014: 117; 2015: 357, 386-389, 509-510). Hasta ese momento, en la amonedación tiberiana nunca apareció individualizada, sino vinculada a diversos emblemas bajo una conducta que pudo verse influenciada por la tendencia de las últimas emisiones augusteas, que solo le dieron autonomía en los reversos de la moneda fraccionaria, la cual no fue acuñada en esta primera etapa del reinado.

Ciertamente, esta emisión supuso una reorientación clara en la estima del tipo epigráfico, porque aunque siguió manteniendo una función complementaria en dos series de dupondios ( $R P C$ I 345-346) y en los ases ( $R P C$ I 349-351), también se independizó sobre valores de múltiplos ( $R P C$ I 348), en una de cuyas series se introdujo dentro de una corona de roble $(R P C$ I 347), composición característica de la amonedación augustea a la que ya no se volvió a recurrir (Aguilera Hernández, 2015: 567-585). Para las siguientes emisiones, constituidas por semis y cuadrantes ( $R P C \mathrm{I}$ 

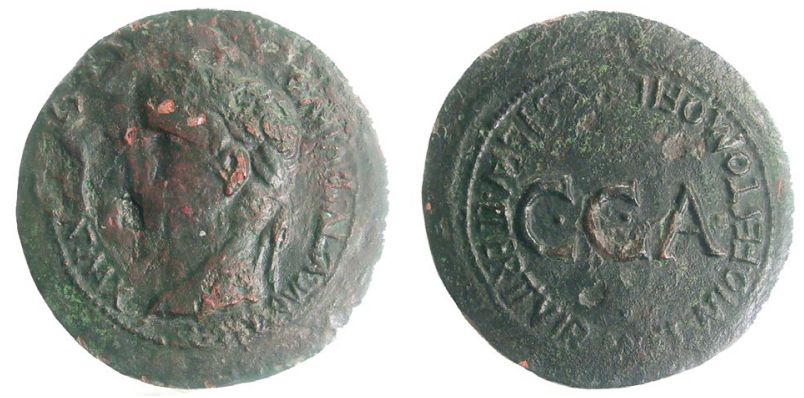

Figura 5: Sestercio (RPC I 359) de Caesar Augusta a nombre de Mn. Flauius Festus y M. Ofillius Siluan. iterum Iluiri con las siglas C C A como tipo principal del reverso, post. 31/32 d.C. (Museo de Zaragoza 87.66.583. Tomado de Domínguez y Aguilera, 2011-2012: 73, n. ${ }^{\circ} 30$ ).

352-353; 354-358 y RPC I S-357A), la sigla se situó en los reversos, entre las astas de los tipo militares siguiendo el modelo observado en Ilici, Acci o Augusta Emerita, hasta que con los duumuiri Mn. Flauius Festus y M. Ofillius Siluan. se transfirió como tipo independiente para los reversos de sestercios (Fig. 5) y dupondios ( $R P C$ I 359-360), exactamente igual que en los semis de sus colegas C. Carri. Aquil. y L. Funi. Vet. $f(R P C$ I 361); y en los de Q. Rosc. y C. Q. Turel? ( $R P C$ I S2-I-361A); en una serie de dupondios de la emisión que documenta la magistratura honorífica de Cayo César, labrada hacia el 33 d.C. (RPC I 363) ${ }^{18}$, o en los sestercios ( $R P C$ I 365-366) a nombre de T. Caecilius Lepidus y C. Aufidius Gemellus, que controlaron la última emisión del reinado. Ello supone un claro testimonio de la consideración que la fórmula epigráfica estaba alcanzando, dentro de un contexto en el que el programa cívico propagandístico basado en la sucesión dinástica y el culto imperial, muy presente en las emisiones cesaraugustanas acuñadas entre el 24-31/32 d.C., entraba en un agotamiento evidente.

Un comportamiento similar mostró Tarraco, pues frente a la tendencia del periodo anterior reservó la sigla C V T T a los reversos de los sestercios, complementando a diversos iconos (RPC I 218, 219, 221, $222,224,225$ y 226), o como tipo individualizado (RPC I 220, 223 y 227) dentro de la corona de roble (Fig. 6) ${ }^{19}$. Ello no excluyó que ocasionalmente también se utilizara en los semis ( $R P C$ I 220) o, incluso, a que se diseñaran dos nuevas fórmulas de menor presencia: C T T (RPC I 229-230) y C V T en las unidades dedicadas a Germánico y Druso el Menor ( $R P C$

18. Es necesario indicar que, en esta emisión, las siglas complementan el busto de la Pietas en el anverso de una serie de unidades (RPC I 362) y al aquila entre signa en el reverso de otra serie de unidades ( $R P C$ I 364). En el anverso, hasta ese momento únicamente habían aparecido en los semis de la novena emisión, la última del reinado de Augusto $(R P C$ I 330-331).

19. No faltan casos en los que se localizan sobre ases ( $R P C$ I 228-230, 232 y 233) o semis ( $R P C$ I 231), pero siempre en relación con otras imágenes.
I 232), y en los bronces que conmemoran a este último y Livia ( $R P C$ I 233), en todos los casos sin actuar como tipo epigráfico independiente. Por el contrario, en Augusta Emerita la aparición del acrónimo C A E no supuso ni su autonomía como emblema propio, ni el descarte de otras referencias toponímicas, aunque ahora se destinó también a nominales de mayor valor y a ambas caras. Sobre los anversos está presente en las emisiones consagradas al Diuus Augustus (RPC I 30$37)^{20} \mathrm{y}$, en los reversos, en ases junto al templo tetrástilo dedicado a la AETERNITATI AVGVSTAE (RPC I 29); en los dupondios de Iulia Augusta (RPC I 39); en los ases que homenajearon a esta junto con su hijo Tiberio ( $R P C \mathrm{I} 40)$ y en los ases y semis ( $R P C$ I 47-49) que cerraron la actividad monetaria del taller. Mucho más circunstanciales se revelan los casos en los que se grabó de manera conjunta en ambas caras, siempre sobre valores de semis ( $R P C$ I 37; $R P C$ I S2-I-37A y RPC S3-I-49A).

Ilici se mantuvo dentro de la tradición local iniciada con Augusto, y nunca incluyó el tipo epigráfico en solitario en las tres emisiones acuñadas durante el gobierno de Tiberio (RPC I 194-195; 196-197 y 198199), aunque consagró definitivamente la fórmula $C$ o (Q) I I A, a la par que Acci solo utilizó el acrónimo $\mathrm{C}$ I G A en los reversos de los dupondios (RPC I 137) de la primera emisión del reinado, que se fechan en el 14-19 d.C. por referir a Druso el Menor y a Germánico como duumuiri de la colonia. Para la siguiente se batieron dupondios, ases y semis (RPC I 137-140) con el letrero C I G ACCI en los reversos de los dos últimos valores en conexión con las insignias legionarias características de la colonia o a los instrumentos sacerdotales del apex, simpulum y lituus, aunque para los múltiplos se prefirió una corona rodeando el rótulo COL IVL GEM ACCI, prueba del valor significativo que este tipo de menciones estaban adquiriendo en determinadas colonias pero, en este caso, mediante el uso de una abreviatura.
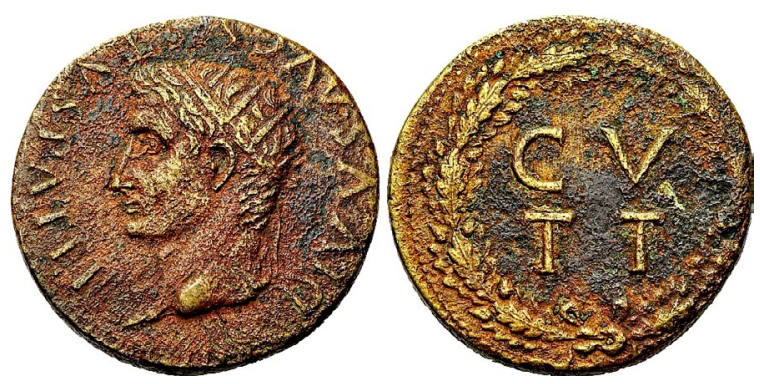

Figura 6: Sestercio (RPC I 220) de Tarraco con las siglas C V $\mathrm{T} T$ en el interior de una láurea como tipo principal del reverso, 14-19 d.C. (Jesús Vico S.A. Auction 131, 9 October 2012, lot. 611 de la ex-colección Cervera. Ex HSA-23842. Recuperado de: https://www.numisbids.com)

20. En los semis ( $R P C$ I 37) la mención epigráfica también figura en el reverso. 
En Carthago Noua lo más destacable en este campo fueron las variaciones toponímicas que ofrecen sus emisiones, pero siempre con valor complementario al de las imágenes. Como C(olonia) V(rbs) I(ulia) $N$ (oua) C(arthago) la tenemos en ases y semis ( $R P C$ I 179-180) a nombre de los césares Nerón y Druso como quinquenales; y en los ases, semis y cuadrantes (RPC I 182-184) suscritos por Cayo César, también como quinquenal, podemos encontrarnos IN $V(r b e)$ I(ulia) N(oua) K(arthagine) o C(olonia) V(rbs) I(ulia) $N$ (oua) K(arthago). En lo que afecta a Celsa, las dos emisiones de Tiberio confirman el uso de la leyenda C V I CEL (RPC I 279) o simplemente CELSA (RPC I 280) en un comportamiento contrario al que revela Calagurris, pues si el municipio se mostró dubitativo en el uso de la sigla $M$ (unicipium) C(alagurris) I(ulia) con Augusto, en sus tres emisiones tiberianas ( $R P C \mathrm{I}$ 448,449 y 450-451) resultó la única referencia utilizada en el reverso en asociación al toro parado, con la salvedad de los semis de los ediles L. Val. Flauo y $T$. Val. Merula, que volvió al anverso como en las emisiones posteriores al 2 a.C.

\section{EVOLUCIÓN DE LAS SIGLAS Y ACRÓNIMOS EN EL REINADO DE CALÍGULA}

Bajo Calígula, únicamente Caesar Augusta y Carthago Noua continuaron emitiendo con sus características siglas, pues las restantes cecas estaban ya clausuradas a excepción de $A c c i^{21}$. La tendencia general fue continuista con la marcada por la amonedación previa y en Caesar Augusta, que ya no acuñó divisores, la sigla siguió figurando como complemento a otras imágenes y como tipo independiente (Fig. 7) en sestercios y dupondios ( $R P C$ I 370, 373, 377, 380, 384 y 385) $)^{22}$, mientras que en Carthago Noua, la última emisión (RPC I 185-186) a nombre de Cn. Atellius Flaccus y Cn. Pompeius Flaccus, documenta el carácter adicional de la fórmula epigráfica $V(r b s)$ I(ulia) $N($ oua $)$ C(arthago).

21. Por su parte, $A c c i$ utilizó la abreviatura C I G ACCI en ases (RPC I 139) y semis (RPC I 140), y COL IVL GEM ACCI, inscrita en una corona de roble, en los anversos de los dupondios (RPC I 138). Ello permite comprobar que la consideración de los tipos epigráficos en la ceca siguió muy de cerca al proceso de Tarraco o Caesar Augusta, pero bajo una fórmula epigráfica distinta.

22. Siendo más difícil de determinar la autenticidad de unos ases que, supuestamente, lucen en el reverso la cabeza de Calígula laureada a derecha junto a la leyenda GERMANICVS CAESAR TI AVG F DIVI AVG N y, en el reverso, el acrónimo abarcando todo el campo monetal rodeado por la leyenda SCIPIONE ET MONTANO II VIRI. Esta unidad ya fue descartada por Trillmich (1973: 164, n. $\left.{ }^{\circ} 105\right)$ así como en el RPC I(119), aunque García-Bellido y Blázquez Cerrato (2001: vol. II, 81, n. ${ }^{\circ}$ 61) sí la recogen a la espera de confirmación.
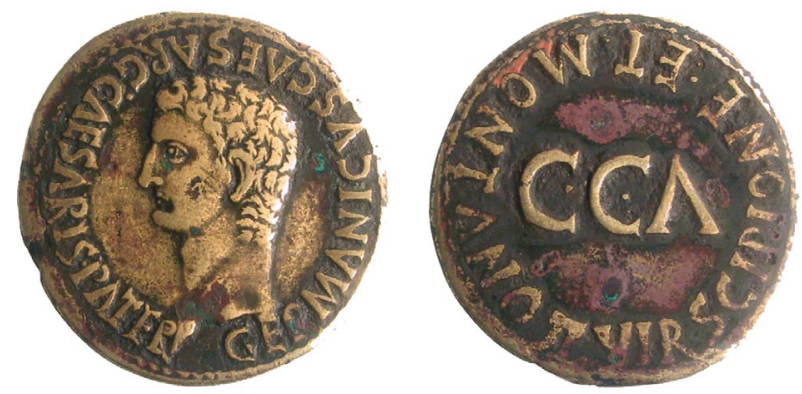

Figura 7: Dupondio (RPC I 377) de Caesar Augusta a nombre de Scipione y Montano con el tipo epigráfico C C A como composición principal del reverso, 38-39 d.C. (Museo de Zaragoza 8207. Tomado de: Domínguez y Aguilera, 2011-2012: 75-76, n. $\left.{ }^{\circ} 39\right)$.

\section{CONCLUSIONES}

A modo de recapitulación, podemos confirmar que el uso de siglas y acrónimos toponímicos tuvo mayor protagonismo en las colonias de la Tarraconense que en las restantes cecas hispanas, siendo Calagurris el único municipio que recurrió a ellas. Su función se circunscribió a dos ámbitos distintos pero no excluyentes: por un lado acompañar a las imágenes emblemáticas de cada taller en los reversos o a los retratos de divinidades o emperadores en los anversos, modalidad que dominó o fue la única en Lepida-Celsa, Acci, Ilici, Carthago Noua y Calagurris. En cambio, Augusta Emerita, Tarraco y Caesar Augusta compaginaron este uso con una distinción que, a partir del 2 a.C. en los dos primeros casos, y desde el 7 d.C. en el tercero, condujo a que estas menciones epigráficas también se constituyeran en un tipo cívico más con entidad propia aunque, en principio, sobre pequeños valores.

Durante el reinado de Tiberio, tanto Tarraco como Caesar Augusta las sometieron a un proceso evolutivo que concluyó con una revalorización fruto del apego de estas comunidades ciudadanas. Sin embargo, mientras que la primera lo hizo dentro de las emisiones que dedicó al culto imperial y a la sucesión dinástica, Caesar Augusta prefirió hacerlo a partir del 31/32 d.C., cuando esta misma temática entró en un claro agotamiento que llevó a que su sigla sobre valores de múltiplos dominara las últimas series del reinado, hasta el punto de conformar un periodo transicional hacia los nuevos programas cívico-propagandísticos diseñados con Calígula, gobierno bajo el cual se mantuvo su importancia. En uno y otro caso, podemos concluir que, al igual que las imágenes, estas fórmulas llegaron a actuar como auténticos emblemas capaces de aglutinar en torno a ellas los sentimientos de pertenencia de tarraconenses y cesaraugustanos a un cuerpo cívico común. 
CATÁLOGO DE ACRÓNIMOS Y SIGLAS EN LAS ACUÑACIONES CÍVICAS HISPANAS

\begin{tabular}{|c|c|c|c|c|c|c|}
\hline CECA & $\begin{array}{c}\text { ACRÓNIMO } \\
\text { / SIGLA }\end{array}$ & VALOR & MAGISTRADOS & CRONOLOGÍA & POSICIÓN & $\begin{array}{l}\text { IMAGEN (a la } \\
\text { que se vincula } \\
\text { en la misma } \\
\text { cara) }\end{array}$ \\
\hline \multirow[t]{15}{*}{$\begin{array}{l}\text { Augusta } \\
\text { Emerita }\end{array}$} & $\mathrm{C}(\mathrm{O}) \mathrm{A} \mathrm{E}$ & Semis ( $R P C$ I 16$)$ & & Post. 2 a.C. & Reverso & $\begin{array}{l}\text { Aquila entre dos } \\
\text { estandartes }\end{array}$ \\
\hline & \multirow[t]{14}{*}{$\mathrm{CAE}$} & Semis ( $R P C$ I 18$)$ & & Post. 2 a.C. & Reverso & $\begin{array}{l}\text { Aquila entre dos } \\
\text { estandartes }\end{array}$ \\
\hline & & $\begin{array}{l}\text { Cuadrante } \\
\text { (RPC I 19) }\end{array}$ & & Post. 2 a.C. & Reverso & $\begin{array}{c}\text { Pátera, lituo y } \\
\text { jarra }\end{array}$ \\
\hline & & As (RPC I 29) & & Reinado de Tiberio & Reverso & $\begin{array}{l}\text { Templo } \\
\text { tetrástilo }\end{array}$ \\
\hline & & $\begin{array}{l}\text { Dupondio } \\
(R P C \text { I 30) }\end{array}$ & & Reinado de Tiberio & Anverso & $\begin{array}{c}\text { Cabeza del } \\
\text { Diuus Augustus } \\
\text { a izq. }\end{array}$ \\
\hline & & As (RPC I 31-32) & & Reinado de Tiberio & Anverso & $\begin{array}{c}\text { Cabeza del } \\
\text { Diuus Augustus } \\
\text { a izq. o dcha. }\end{array}$ \\
\hline & & As ( $R P C$ I 33-34) & & Reinado de Tiberio & Anverso & $\begin{array}{c}\text { Cabeza del } \\
\text { Diuus Augustus } \\
\text { a izq. con o sin } \\
\text { estrella }\end{array}$ \\
\hline & & As (RPC I 35) & & Reinado de Tiberio & Anverso & $\begin{array}{c}\text { Cabeza del } \\
\text { Diuus Augustus } \\
\text { a dcha. }\end{array}$ \\
\hline & & As (RPC I 36) & & Reinado de Tiberio & Anverso & $\begin{array}{c}\text { Cabeza del } \\
\text { Diuus Augustus } \\
\text { a izq. con o sin } \\
\text { estrella }\end{array}$ \\
\hline & & Semis ( $R P C$ I 37$)$ & & Reinado de Tiberio & $\begin{array}{l}\text { Anverso / } \\
\text { reverso }\end{array}$ & $\begin{array}{c}\text { Cabeza del } \\
\text { Diuus Augustus } \\
\text { a izq. / Aquila } \\
\text { entre dos } \\
\text { estandartes }\end{array}$ \\
\hline & & $\begin{array}{c}\text { Semis }(R P C \mathrm{I} \\
\mathrm{S} 2-\mathrm{I}-37 \mathrm{~A})\end{array}$ & & Reinado de Tiberio & $\begin{array}{l}\text { Anverso / } \\
\text { reverso }\end{array}$ & $\begin{array}{c}\text { Cabeza del } \\
\text { Diuus Augustus } \\
\text { a izq. / Aquila } \\
\text { entre dos } \\
\text { estandartes }\end{array}$ \\
\hline & & $\begin{array}{c}\text { Dupondio ( } R P C \\
\text { I 39) }\end{array}$ & & Reinado de Tiberio & Reverso & $\begin{array}{c}\text { Livia } \\
\text { entronizada a } \\
\text { dcha. portando } \\
\text { cetro y dos } \\
\text { espigas }\end{array}$ \\
\hline & & As (RPC I 40) & & Reinado de Tiberio & Reverso & $\begin{array}{c}\text { Cabeza de Livia } \\
\text { a dcha. }\end{array}$ \\
\hline & & As (RPC I 47-48) & & Reinado de Tiberio & Reverso & $\begin{array}{c}\text { Templo } \\
\text { tetrástilo }\end{array}$ \\
\hline & & $\begin{array}{c}\text { Semis }(R P C \\
\text { I } 49 \text { y } R P C \text { I } \\
\text { S3-I-49A) }\end{array}$ & & Reinado de Tiberio & Reverso & $\begin{array}{l}\text { Aquila entre dos } \\
\text { estandartes }\end{array}$ \\
\hline
\end{tabular}




\begin{tabular}{|c|c|c|c|c|c|c|}
\hline \multirow[t]{3}{*}{$A c c i$} & \multirow[t]{2}{*}{ C I G AC } & As (RPC I 133) & & $\begin{array}{l}\text { Reinado de } \\
\text { Augusto }\end{array}$ & Reverso & $\begin{array}{l}\text { Dos aquilae } \\
\text { entre dos } \\
\text { estandartes }\end{array}$ \\
\hline & & $\begin{array}{c}\text { Semis }(R P C I \\
134)\end{array}$ & & $\begin{array}{l}\text { Reinado de } \\
\text { Augusto }\end{array}$ & $\begin{array}{l}\text { Anverso / } \\
\text { reverso }\end{array}$ & $\begin{array}{l}\text { Dos aquilae } \\
\text { entre dos } \\
\text { estandartes }\end{array}$ \\
\hline & C I G A & $\begin{array}{l}\text { Dupondio }(R P C \\
\text { I 137) }\end{array}$ & & $\begin{array}{l}\text { Reinado de Tiberio } \\
\text { (14-19 d.C.) }\end{array}$ & Reverso & $\begin{array}{c}\text { Cabezas } \\
\text { enfrentadas de } \\
\text { Germánico y } \\
\text { Druso }\end{array}$ \\
\hline \multirow[t]{7}{*}{$\begin{array}{c}\text { Carthago } \\
\text { Noua }\end{array}$} & C V I N & $\begin{array}{c}\text { Semis }(R P C \mathrm{I} \\
151)\end{array}$ & & Pre-augustea? & Reverso & $\begin{array}{l}\text { Estatua sobre } \\
\text { pedestal a izq. }\end{array}$ \\
\hline & \multirow[t]{2}{*}{ V I N K } & $\begin{array}{c}\text { Semis }(R P C I \\
174-177)\end{array}$ & $\begin{array}{l}\text { P. Turullius IIuir } \\
\text { quinquen. y M. } \\
\text { Postum. Albinus } \\
\text { Iluir quinqu. iter }\end{array}$ & $\begin{array}{l}\text { Reinado de } \\
\text { Augusto? }\end{array}$ & $\begin{array}{l}\text { Anverso / } \\
\text { reverso }\end{array}$ & $\begin{array}{l}\text { Cuadriga a dcha. } \\
\text { o izq. Delante: } \\
\text { uexillum } \\
\text { / Templo } \\
\text { tetrástilo }\end{array}$ \\
\hline & & $\begin{array}{c}\text { Cuadrante ( } R P C \\
\text { I 178) }\end{array}$ & $\begin{array}{l}\text { P Turullius IIuir } \\
\text { quinquen. y M. } \\
\text { Postum. Albinus } \\
\text { IIuir quinqu. iter }\end{array}$ & $\begin{array}{l}\text { Reinado de } \\
\text { Augusto? }\end{array}$ & $\begin{array}{l}\text { Anverso / } \\
\text { reverso }\end{array}$ & $\begin{array}{l}\text { Vexillum entre } \\
\text { dos fasces } \\
\text { / Lituus, } \\
\text { simpulum y } \\
\text { aspergillum }\end{array}$ \\
\hline & C V I N C & $\begin{array}{c}\text { As }(R P C \text { I } 179- \\
180) \text { y semis } \\
(R P C \text { I } 181)\end{array}$ & $\begin{array}{l}\text { Nero et Drusus } \\
\text { Caesares quinq. }\end{array}$ & $\begin{array}{l}\text { Reinado de Tiberio } \\
\quad(23-29 \text { d.C. })\end{array}$ & Reverso & $\begin{array}{c}\text { Cabezas } \\
\text { enfrentadas de } \\
\text { Nerón y Druso }\end{array}$ \\
\hline & $\begin{array}{c}\text { IN (o C) } \\
\text { V I N K(AR) }\end{array}$ & As (RPC I 182) & $\begin{array}{l}\text { C. Caesar Ti. } n . \\
\text { quinq. }\end{array}$ & $\begin{array}{l}\text { Reinado de Tiberio } \\
\quad(31-37 \text { d.C. })\end{array}$ & Reverso & $\begin{array}{c}\text { Cabeza desnuda } \\
\text { de Calígula a } \\
\text { izq. }\end{array}$ \\
\hline & IN V I N K & $\begin{array}{l}\text { Semis }(R P C \text { I } \\
182) \text { y cuadrante } \\
(R P C \text { I 183) }\end{array}$ & $\begin{array}{l}\text { C. Caesar Ti. } n . \\
\text { quinq. }\end{array}$ & $\begin{array}{l}\text { Reinado de Tiberio } \\
\text { (31-37 d.C.) }\end{array}$ & Reverso & $\begin{array}{c}\text { Cabeza desnuda } \\
\text { de Calígula a } \\
\text { izq. }\end{array}$ \\
\hline & V I N C & $\begin{array}{l}\text { As }(R P C \text { I } 185) \\
\text { y semis }(R P C \mathrm{I} \\
186)\end{array}$ & $\begin{array}{l}\text { Cn. Atel. Flac. y } \\
\text { Cn. Pom. Flac. } \\
\text { Iluir q. }\end{array}$ & $\begin{array}{c}\text { Reinado de } \\
\text { Calígula (37-41 } \\
\text { d.C.) }\end{array}$ & Reverso & $\begin{array}{c}\text { Cabeza de Salus } \\
\text { a dcha. }\end{array}$ \\
\hline \multirow[t]{6}{*}{ Ilici } & C C IL A & $\begin{array}{c}\text { Semis }(R P C \mathrm{I} \\
189-191)\end{array}$ & $\begin{array}{l}\text { L. Manlius y } T \text {. } \\
\text { Petronius IIuir }\end{array}$ & $\begin{array}{l}\text { Reinado de } \\
\text { Augusto }\end{array}$ & Reverso & $\begin{array}{c}\text { Aquila y } \\
\text { uexillum } \text { entre } \\
\text { dos estandartes }\end{array}$ \\
\hline & C I IL A & $\begin{array}{c}\text { Semis }(R P C \mathrm{I} \\
192-193)\end{array}$ & $\begin{array}{l}\text { Q. Papir. Car. y } Q \text {. } \\
\text { Tere. Mont. IIuir q. }\end{array}$ & $\begin{array}{c}\text { Reinado de } \\
\text { Augusto }\end{array}$ & Reverso & $\begin{array}{c}\text { Templo } \\
\text { tetrástilo } \\
\end{array}$ \\
\hline & $C(o-Q)$ I I A & $\begin{array}{l}\text { As }(R P C \mathrm{I} 194) \\
\text { y semis }(R P C \mathrm{I} \\
195)\end{array}$ & $\begin{array}{l}\text { T. Coelius Proculus } \\
\text { y M. Aemilius } \\
\text { Seuerus } q .\end{array}$ & Reinado de Tiberio & Reverso & $\begin{array}{l}\text { Aquila entre dos } \\
\text { estandartes }\end{array}$ \\
\hline & \multirow[t]{3}{*}{ C I I A } & $\begin{array}{c}\text { As }(R P C \text { I } 196) \\
\text { y semis }(R P C \mathrm{I} \\
197)\end{array}$ & $\begin{array}{l}\text { M. Iulius Settal. y } \\
\text { L. Sesti. Celer IIuir }\end{array}$ & Reinado de Tiberio & Reverso & $\begin{array}{l}\text { Altar de la Salus } \\
\text { Augusta }\end{array}$ \\
\hline & & As (RPC I 198) & $\begin{array}{l}\text { L. Ter. Lon. y L. } \\
\text { Pap. Auit. IIuir q. }\end{array}$ & Reinado de Tiberio & Reverso & $\begin{array}{l}\text { Dos togados } \\
\text { dándose la } \\
\text { mano sobre un } \\
\text { thymiaterion }\end{array}$ \\
\hline & & $\begin{array}{c}\text { Semis }(R P C \mathrm{I} \\
199)\end{array}$ & $\begin{array}{l}\text { L. Ter. Lon. y L. } \\
\text { Pap. Auit. Iluir q. }\end{array}$ & Reinado de Tiberio & Reverso & $\begin{array}{l}\text { Vexillum entre } \\
\text { dos aquilae }\end{array}$ \\
\hline
\end{tabular}




\begin{tabular}{|c|c|c|c|c|c|c|}
\hline \multirow[t]{11}{*}{ Tarraco } & \multirow[t]{4}{*}{$\mathrm{CVT}$} & As (RPC I 210) & & $\begin{array}{c}\text { Reinado de } \\
\text { Augusto (2 a.C.-4 } \\
\text { d C.) }\end{array}$ & Reverso & $\begin{array}{c}\text { Cabezas } \\
\text { enfrentadas de } \\
\text { Cayo y Lucio }\end{array}$ \\
\hline & & $\begin{array}{c}\text { Cuadrante (RPC } \\
\text { I 214) }\end{array}$ & & $\begin{array}{c}\text { Reinado de } \\
\text { Augusto (2 a.C.-4 } \\
\text { d C.) }\end{array}$ & Reverso & $\begin{array}{l}\text { Actúa como tipo } \\
\text { principal dentro } \\
\text { de una corona }\end{array}$ \\
\hline & & As (RPC I 215) & & $\begin{array}{c}\text { Reinado de } \\
\text { Augusto (4-14 } \\
\text { d.C.) }\end{array}$ & Reverso & $\begin{array}{c}\text { Cabeza desnuda } \\
\text { de Tiberio a } \\
\text { dcha. }\end{array}$ \\
\hline & & $\begin{array}{l}\text { Semis ( } R P C \text { I } \\
216) \text { y cuadrante } \\
(R P C \text { I 217) }\end{array}$ & & $\begin{array}{l}\text { Reinado de } \\
\text { Augusto (4-14 } \\
\text { d.C.) }\end{array}$ & Reverso & $\begin{array}{l}\text { Actúa como tipo } \\
\text { principal dentro } \\
\text { de una corona }\end{array}$ \\
\hline & \multirow[t]{3}{*}{$\mathrm{CVTT}$} & $\begin{array}{c}\text { Sestercio }(R P C \text { I } \\
218,221,225)\end{array}$ & & Reinado de Tiberio & Reverso & Altar con palma \\
\hline & & $\begin{array}{c}\text { Sestercio } \\
(R P C \text { I } \\
219,222,224, \\
226)\end{array}$ & & Reinado de Tiberio & Reverso & Templo octástilo \\
\hline & & $\begin{array}{c}\text { Sestercio }(R P C \text { I } \\
220,223,227)\end{array}$ & & Reinado de Tiberio & Reverso & $\begin{array}{l}\text { Actúa como tipo } \\
\text { principal dentro } \\
\text { de una corona }\end{array}$ \\
\hline & $\mathrm{CTT}$ & $\begin{array}{l}\text { As }(R P C \text { I } \\
229-230)\end{array}$ & & Reinado de Tiberio & Reverso & $\begin{array}{c}\text { Cabeza del } \\
\text { Diuus Augustus } \\
\text { a izq. }\end{array}$ \\
\hline & C V T T & $\begin{array}{c}\text { Semis }(R P C \mathrm{I} \\
231)\end{array}$ & & Reinado de Tiberio & Reverso & Altar con palma \\
\hline & \multirow[t]{2}{*}{$\mathrm{CVT}$} & As (RPC I 232) & & $\begin{array}{l}\text { Reinado de Tiberio } \\
\quad(15-19 \text { d.C. })\end{array}$ & Reverso & $\begin{array}{c}\text { Cabezas } \\
\text { enfrentadas de } \\
\text { Germánico y } \\
\text { Druso }\end{array}$ \\
\hline & & As (RPC I 233) & & $\begin{array}{l}\text { Reinado de Tiberio } \\
\quad(22-23 \text { d.C. })\end{array}$ & Reverso & $\begin{array}{c}\text { Cabezas } \\
\text { enfrentadas de } \\
\text { Druso y Livia }\end{array}$ \\
\hline \multirow[t]{6}{*}{$\begin{array}{l}\text { Lepida } \\
\text { /Celsa }\end{array}$} & \multirow[t]{6}{*}{ C V I L } & As (RPC I 261) & $\begin{array}{l}\text { M. Ful. y C. Otac. } \\
\text { pr. quin }\end{array}$ & 44-36 a.C. & Anverso & $\begin{array}{c}\text { Busto de } \\
\text { Victoria a dcha. } \\
\text { con palma sobre } \\
\text { el hombro }\end{array}$ \\
\hline & & As (RPC I 262) & $\begin{array}{l}\text { C. Balbus y L. } \\
\text { Porcius Iluir }\end{array}$ & 44-36 a.C. & Anverso & $\begin{array}{c}\text { Busto de } \\
\text { Victoria a dcha. } \\
\text { con palma sobre } \\
\text { el hombro }\end{array}$ \\
\hline & & $\begin{array}{c}\text { Semis }(R P C I \\
265)\end{array}$ & $\begin{array}{l}\text { L. Semp. Max. у M. } \\
\text { Caec. aed. }\end{array}$ & 44-36 a.C. & Anverso & $\begin{array}{c}\text { Cabeza de } \\
\text { Hércules a dcha. } \\
\text { con clava }\end{array}$ \\
\hline & & $\begin{array}{c}\text { Semis }(R P C \mathrm{I} \\
266)\end{array}$ & $\begin{array}{l}\text { L. Calp. y Sex. Nig. } \\
\text { aed. }\end{array}$ & 44-36 a.C. & Anverso & $\begin{array}{l}\text { Busto radiado } \\
\text { del sol de frente }\end{array}$ \\
\hline & & $\begin{array}{c}\text { Cuadrante }(R P C \\
\text { I 268) }\end{array}$ & $\begin{array}{l}\text { L. Calp. y Sex. Nig. } \\
\text { aed. }\end{array}$ & 44-36 a.C. & Anverso & Jabalí a dcha. \\
\hline & & $\begin{array}{c}\text { Cuadrante }(R P C \\
\text { I 277) }\end{array}$ & $\begin{array}{l}\text { L. Aufid. Pansa y } \\
\text { Sex. Pomp. Niger } \\
\text { aed. }\end{array}$ & $\begin{array}{l}\text { Reinado de } \\
\text { Augusto }\end{array}$ & Reverso & $\begin{array}{l}\text { Actúa como tipo } \\
\text { principal }\end{array}$ \\
\hline
\end{tabular}




\begin{tabular}{|c|c|c|c|c|c|c|}
\hline \multirow[t]{18}{*}{$\begin{array}{l}\text { Caesar } \\
\text { Augusta }\end{array}$} & \multirow[t]{18}{*}{$\mathrm{C} \mathrm{CA}$} & $\begin{array}{c}\text { Dupondio }(R P C \mathrm{I} \\
325-326)\end{array}$ & $\begin{array}{l}\text { Tib. Clod. Flauus } \\
\text { praef. German. y } \\
\text { L. Iuuent. Lupercus } \\
\text { IIuir }\end{array}$ & $\begin{array}{l}\text { Reinado de } \\
\text { Augusto. (c. } 7 \\
\text { d.C.) }\end{array}$ & Reverso & $\begin{array}{c}\text { Yunta } \\
\text { fundacional a } \\
\text { dcha. o izq. }\end{array}$ \\
\hline & & $\begin{array}{l}\text { As }(R P C \text { I } \\
327-328)\end{array}$ & $\begin{array}{l}\text { Tib. Clod. Flauus } \\
\text { praef. German. y } \\
\text { L. Iuuent. Lupercus } \\
\text { Iluir }\end{array}$ & $\begin{array}{c}\text { Reinado de } \\
\text { Augusto (c. } 7 \text { d.C.) }\end{array}$ & Reverso & $\begin{array}{c}\text { Toro mitrado } \\
\text { a izq. }\end{array}$ \\
\hline & & $\begin{array}{c}\text { Semis }(R P C I \\
329)\end{array}$ & $\begin{array}{l}\text { Tib. Clod. Flauus } \\
\text { praef. German. y } \\
\text { L. Iuuent. Lupercus } \\
\text { Iluir }\end{array}$ & $\begin{array}{c}\text { Reinado de } \\
\text { Augusto (c. } 7 \text { d.C.) }\end{array}$ & Reverso & $\begin{array}{c}\text { Actúa como tipo } \\
\text { principal }\end{array}$ \\
\hline & & $\begin{array}{c}\text { Semis }(R P C \mathrm{I} \\
330-331)\end{array}$ & & $\begin{array}{l}\text { Reinado de } \\
\text { Augusto (c. 13-14 } \\
\text { d.C.) }\end{array}$ & Anverso & $\begin{array}{c}\text { Cabeza laureada } \\
\text { de Augusto a } \\
\text { izq. }\end{array}$ \\
\hline & & $\begin{array}{c}\text { Cuadrante (RPC } \\
\text { I 332) }\end{array}$ & & $\begin{array}{c}\text { Reinado de } \\
\text { Augusto (c. 13-14 } \\
\text { d.C.) }\end{array}$ & Reverso & $\begin{array}{c}\text { Actúa como tipo } \\
\text { principal dentro } \\
\text { de una corona }\end{array}$ \\
\hline & & $\begin{array}{c}\text { As }(R P C \text { I } 333 \text { y } \\
R P C \text { I S-333A })\end{array}$ & & $\begin{array}{l}\text { Reinado de Tiberio } \\
\text { (c. } 14-22 / 23 \text { d.C.) }\end{array}$ & Reverso & $\begin{array}{c}\text { Yunta } \\
\text { fundacional a } \\
\text { dcha. }\end{array}$ \\
\hline & & $\begin{array}{l}\text { As }(R P C \text { I } \\
334-337)\end{array}$ & & $\begin{array}{l}\text { Reinado de Tiberio } \\
\text { (c. } 14-22 / 23 \text { d.C.) }\end{array}$ & Reverso & $\begin{array}{l}\text { Toro mitrado a } \\
\text { dcha. o izq. }\end{array}$ \\
\hline & & As (RPC I 338) & $\begin{array}{l}\text { Lupus IIuir } \\
\text { y Fuluianus } \\
\text { praefectus }\end{array}$ & $\begin{array}{l}\text { Reinado de Tiberio } \\
\text { (c. } 14-22 / 23 \text { d.C.) }\end{array}$ & Reverso & $\begin{array}{c}\text { Yunta } \\
\text { fundacional a } \\
\text { dcha. }\end{array}$ \\
\hline & & As ( $R P C$ I 339) & $\begin{array}{l}\text { Lupus IIuir } \\
\text { y Fuluianus } \\
\text { praefectus }\end{array}$ & $\begin{array}{l}\text { Reinado de Tiberio } \\
\text { (c. } 14-22 / 23 \text { d.C.) }\end{array}$ & Reverso & $\begin{array}{c}\text { Toro mitrado a } \\
\text { dcha. }\end{array}$ \\
\hline & & As $(R P C$ I 340$)$ & & $\begin{array}{l}\text { Reinado de Tiberio } \\
\text { (c. } 14-22 / 23 \text { d.C.) }\end{array}$ & Reverso & $\begin{array}{c}\text { Toro mitrado a } \\
\text { dcha. }\end{array}$ \\
\hline & & As (RPC I 341) & & $\begin{array}{l}\text { Reinado de Tiberio } \\
\text { (post. } 22-23 \text { d.C.) }\end{array}$ & Reverso & $\begin{array}{c}\text { Livia } \\
\text { entronizada } \\
\text { portando cetro y } \\
\text { pátera }\end{array}$ \\
\hline & & $\begin{array}{c}\text { Dupondio }(R P C \\
\text { I 342) }\end{array}$ & $\begin{array}{l}\text { Drusus Nero } \\
\text { Caesares IIuir }\end{array}$ & $\begin{array}{l}\text { Reinado de Tiberio } \\
\text { (c. } 24-28 \text { d.C.) }\end{array}$ & Reverso & $\begin{array}{l}\text { Nerón y Druso } \\
\text { sedentes de } \\
\text { frente }\end{array}$ \\
\hline & & As (RPC I 343) & $\begin{array}{l}\text { Drusus Nero } \\
\text { Caesares IIuir }\end{array}$ & $\begin{array}{l}\text { Reinado de Tiberio } \\
\text { (c. } 24-28 \text { d.C.) }\end{array}$ & Reverso & $\begin{array}{c}\text { Cabezas } \\
\text { enfrentadas de } \\
\text { Nerón y Druso }\end{array}$ \\
\hline & & $\begin{array}{l}\text { Sestercio }(R P C \\
\text { I 344) }\end{array}$ & & $\begin{array}{l}\text { Reinado de Tiberio } \\
\text { (28-29 d.C. })\end{array}$ & Reverso & $\begin{array}{l}\text { Templo } \\
\text { hexástilo }\end{array}$ \\
\hline & & $\begin{array}{c}\text { Dupondio }(R P C \\
\text { I 345) }\end{array}$ & $\begin{array}{c}\text { M.Cato y L } \\
\text { Vettiacus IIuir }\end{array}$ & $\begin{array}{l}\text { Reinado de Tiberio } \\
\text { (31-32 d.C.) }\end{array}$ & Reverso & $\begin{array}{l}\text { Aquila entre dos } \\
\text { estandartes }\end{array}$ \\
\hline & & $\begin{array}{c}\text { Dupondio }(R P C \\
\text { I 346) }\end{array}$ & $\begin{array}{c}\text { M.Cato y L } \\
\text { Vettiacus IIuir }\end{array}$ & $\begin{array}{l}\text { Reinado de Tiberio } \\
\text { (31-32 d.C.) }\end{array}$ & Reverso & $\begin{array}{l}\text { Vexillum entre } \\
\text { dos phalerae } \\
\text { radiadas }\end{array}$ \\
\hline & & $\begin{array}{c}\text { Dupondio }(R P C \text { I } \\
347-348)\end{array}$ & $\begin{array}{c}\text { M.Cato y L } \\
\text { Vettiacus IIuir }\end{array}$ & $\begin{array}{l}\text { Reinado de Tiberio } \\
\text { (31-32 d.C.) }\end{array}$ & Reverso & $\begin{array}{l}\text { Actúa como tipo } \\
\text { principal, en } \\
\text { ocasiones dentro } \\
\text { de una corona }\end{array}$ \\
\hline & & $\begin{array}{c}\text { As ( } R P C \text { I } 349- \\
351 \text { y } R P C \text { I } \\
\text { S3-351A?) }\end{array}$ & $\begin{array}{c}\text { M.Cato y L } \\
\text { Vettiacus IIuir }\end{array}$ & $\begin{array}{l}\text { Reinado de Tiberio } \\
\quad(31-32 \text { d.C.) }\end{array}$ & Reverso & $\begin{array}{l}\text { Yunta } \\
\text { fundacional a } \\
\text { izq. o dcha. }\end{array}$ \\
\hline
\end{tabular}




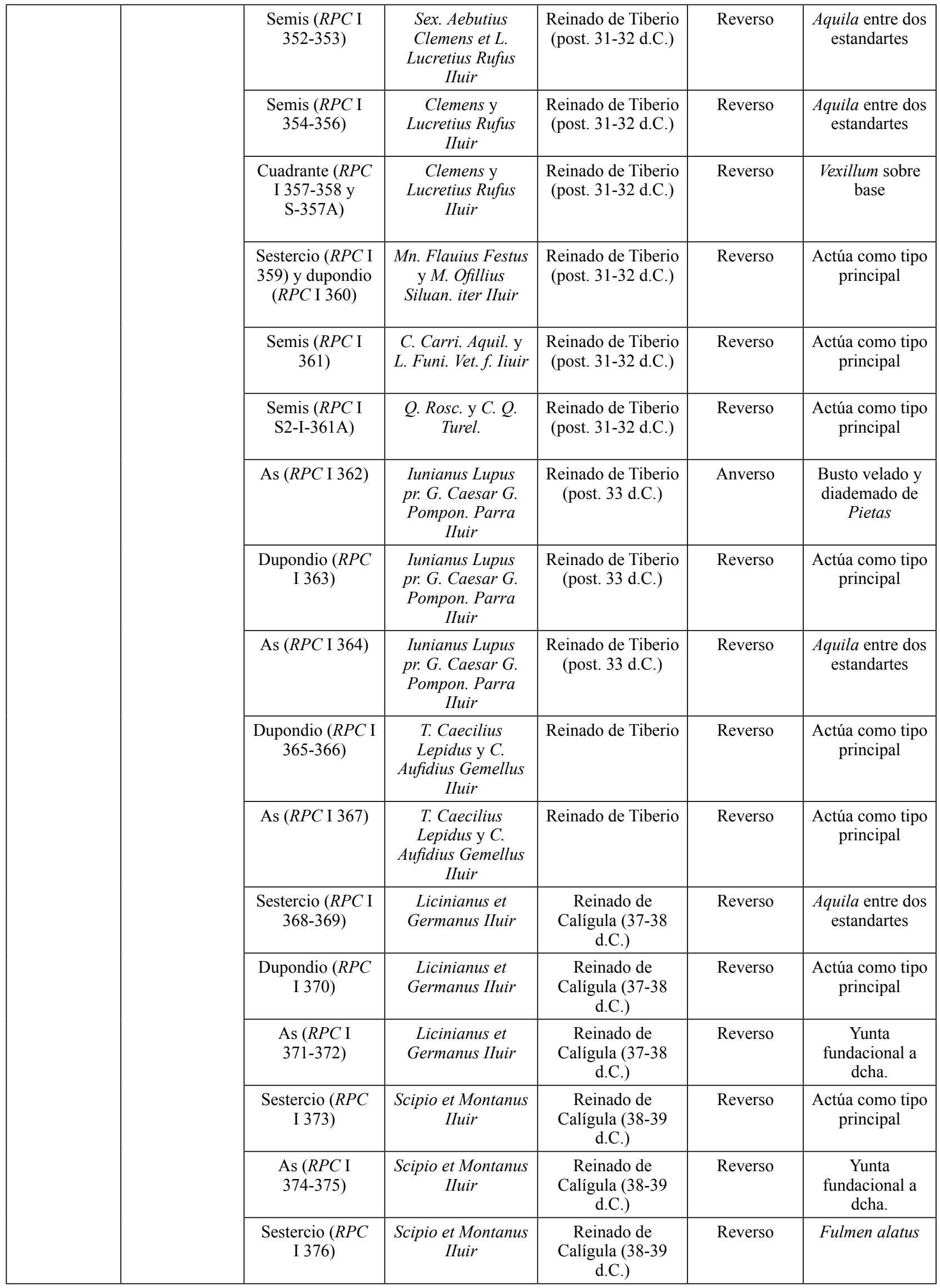




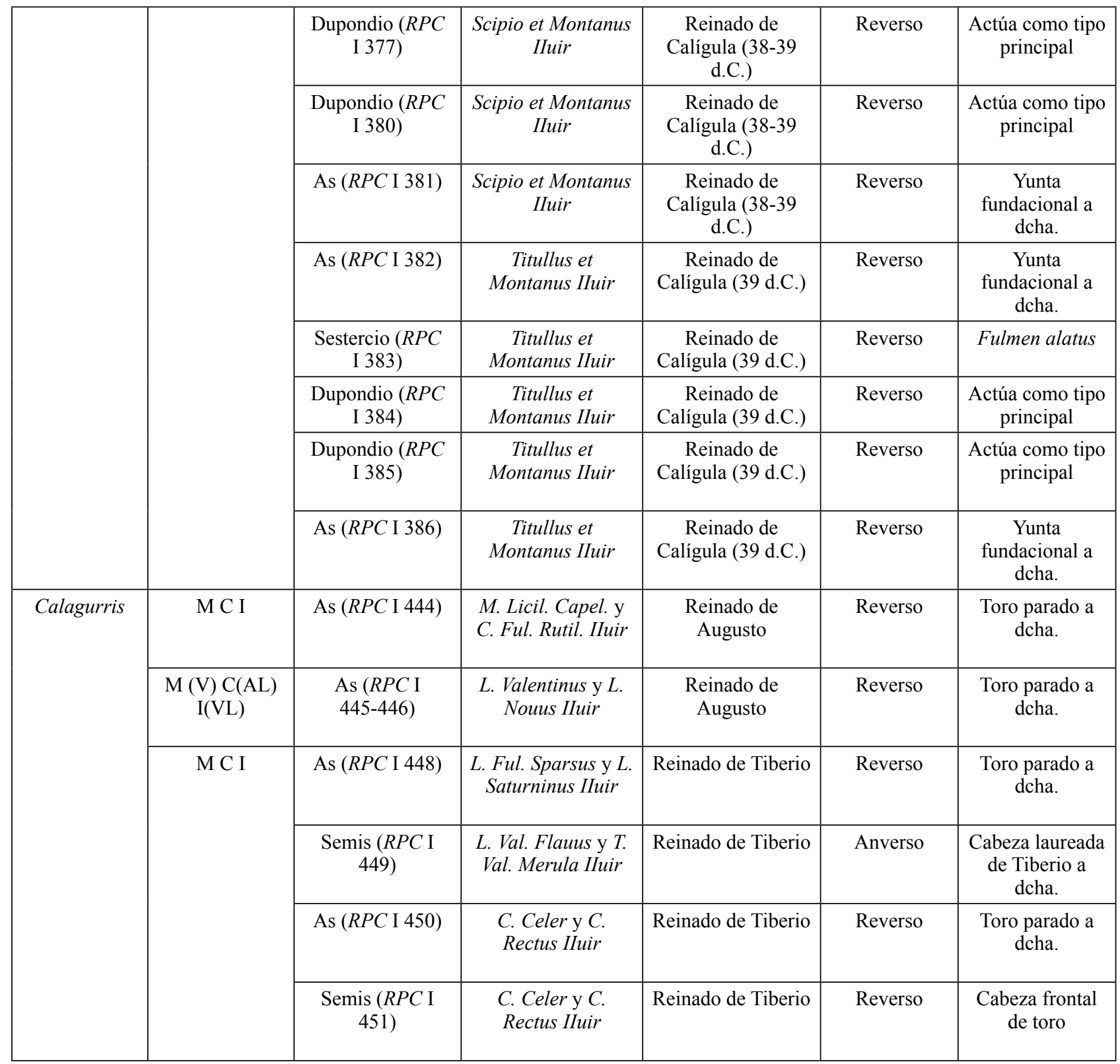

\section{REFERENCIAS}

\section{ABREVIATURAS}

RIC $\mathrm{I}^{2}=$ Sutherland, C.H.V. (1984). The Roman Imperial Coinage, v. I, London: Spink and Son.

$R P C \mathrm{I}=$ Burnett, A., Amandry, M. y Ripollès, P. P. (1992). Roman Provincial Coinage, vol. I. From the death of Caesar to Vitellius (44 BC to AD 69). London-Paris: British Museum Press and Bibliothèque nationale de France.
RPC I S = Burnett, A., Amandry, M. y Ripollès, P. P. (1998). Roman Provincial Coinage.Supplement I. London-Paris: British Museum Press and Bibliothèque nationale de France.

RPC I S2 = Burnett, A., Amandry, M., Ripollès, P.P. y Carradice, D. (2006). Roman Provincial Coinage. Supplement 2. Recuperado de: http://www.uv.es/=ripolles/rpc_s2

RPC I S3 = Amandry, M., Burnett, A., Carradice, D., Ripollès, P.P. y Spoerri Butcher, M. (2014). Roman Provincial Coinage. Supplement 3. Recuperado de: http://numismatics. org/epublications/RPC-S-3-ANS-2014.pdf 
Abascal Palazón, J. M.a (2002). La fecha de la promoción colonial de Carthago Noua y sus repercusiones edilicias. Mastia, 1, 21-44.

Aguilera Hernández, A. (2014). La iconografía de la yunta fundacional en el contexto hispano: los casos de las colonias de Lepida, Augusta Emerita y Caesar Augusta. Numisma, 258, 95-129.

Aguilera Hernández, A. (2015). Imágenes para una nueva Roma: iconografía monetal de la Colonia Caesar Augusta en el periodo julio-claudio. Recuperado de: https://zaguan. unizar.es/record/46985/files/TESIS-2016-004.pdf

Amela Valverde, L. (2013). Sobre el origen de la Colonia C Ilici Augusta. Una nota. Arse, 47, 125-138.

Beltrán Lloris, F. (2002). Identidad cívica y adhesión al príncipe en las monedas municipales hispanas. En F. Marco Simón, F. Pina Polo y J. Remesal Rodríguez (Eds.). Religión $y$ propaganda política en el mundo romano (pp. 159-187). Barcelona: Universitat de Barcelona.

Beltrán Lloris, F. (2014). Colonia Caesar Augusta. Reflexiones sobre el nombre romano de Zaragoza. En A. Duplá Ansuategui, M. ${ }^{a}$ V. Escribano Paños, L. Sancho Rocher y M. ${ }^{a}$ A. Villacampa Rubio (Eds.). Miscelánea de estudios en homenaje a Guillermo Fatás Cabeza (pp. 131-139). Zaragoza: Institución «Fernando el Católico».

Canto, A. M. ${ }^{\text {a }}$ (1989).Colonia Iulia Augusta Emerita: Consideraciones en torno a su fundación y territorio. Gerión, 7 , 149-205.

Cebrián Sánchez, M. Á. (2008). La fundación de la colonia Augusta Emerita y la nueva política monetaria. En M. ${ }^{a}$ P. García-Bellido, A. Mostalac Carrillo, y A. Jiménez Díez (Coords.). Del «imperivm» de Pompeyo a la «avctoritas» de Augusto: homenaje a Michael Grant(Zaragoza, 2007) (pp. 243-250). Madrid: Consejo Superior de Investigaciones Científicas.

Cebrián Sánchez, M. Á. (2013). La ceca romana de Augusta Emerita. Montpellier: OMNI.

Chaves Tristán, F. (1976). Las monedas de Acci. Numisma, 138-143, 141-158.

Domínguez Arranz, A. y Aguilera Hernández, A. (20112012). Caesar Augusta en imágenes: la colección de monedas del Museo de Zaragoza. Acta Numismàtica, 41/42, 63-84.

Domínguez Arranz, A. y Aguilera Hernández, A. (2012). Ritus sagrats i sacerdots. En M. Campo (Ed.). Déus i mites de l'antiguitat. L'evidència de la moneda d'Hispània (pp. 7277). Barcelona: Museo Nacional de Arte de Cataluña.

Donati, A. (2002). Epigrafia romana. La comunicazione nell antichità. Bologna: Ed. Il Mulino.

García-Bellido, M. ${ }^{a}$ P. (2003). La historia de la Colonia Lepida-Celsa según sus documentos numismásticos: su ceca imperial. Archivo Español de Arqueología, 76, 273-290. DOI: https://doi.org/10.3989/aespa.2003.v76.119

García-Bellido, M. ${ }^{a}$ P. y Blázquez Cerrato, C. (2001). Diccionario de cecas y pueblos hispánicos. Madrid: Consejo Superior de Investigaciones Científicas.
Gómez Barreiro, M. (2003). El papel de la colonia de Caesaraugusta en el contexto imperial augusteo. El testimonio histórico de la numismática. Archivo Español de Arqueologia, 76, 291-307. DOI: https://doi.org/10.3989/aespa.2003. v76.120

Gómez Barreiro, M. (2008). Historia de la investigación sobre la ceca de Caesaraugusta. Numisma, 252, 83-120.

Gómez Pantoja, J. (1994). Germánico y Caesaraugusta. Polis, 6, 169-202.

Hurtado Mullor, T. (2013). Las emisiones monetarias de la Colonia Victrix Iulia Lepida-Celsa. Recuperado de: http:// roderic.uv.es/handle/10550/30411

Llorens Forcada, M. ${ }^{a}$ del M. (1987). La ceca de Ilici. Valencia: Universidad de Valencia. Facultad de Geografía e Historia.

Llorens Forcada, M. ${ }^{a}$ del M. (1994). La ciudad de Carthago Nova: las emisiones romanas. Murcia: Universidad de Murcia.

Palao Vicente, J. J. (2010). Una aproximación al estudio de las relaciones entre militares y civiles en Hispania durante el alto imperio. En J.J. Palao Vicente (Ed.). Militares y civiles en la Antigua Roma. Dos mundos diferentes, dos mundos unidos (pp. 165-196). Salamanca: Ediciones Universidad Salamanca.

Ripollès Alegre, P. P. (2010). Las acuñaciones provinciales romanas de Hispania. Madrid: Real Academia de la Historia.

Ripollès Alegre, P. P. (2014). La política monetaria de los romanos durante la época republicana en la península ibérica y las emisiones locales. AIIN, 60, 19-83.

Ruiz Trapero, M. (1968). Las acuñaciones hispano-romanas de Calagurris: su ordenación cronológica y su trascendencia histórica. Barcelona: Asociación Numismática Española.

Sabio González, R. (2011). La propaganda augustea a través de los nombres de las ciudades hispanas. Anas, 24, 145-190.

Sabio González, R. (2014). La toponimia oficial augustea en la península Ibérica: nómina de núcleos poblacionales y principios de aplicación. ETF(hist), 27, 249-265.

Saquete Chamizo, J. C. (2010). Del mundo militar al mundo civil: los veteranos militares y algunas colonias de Augusto en Hispania. En J.J. Palao Vicente (Ed.). Militares y civiles en la Antigua Roma. Dos mundos diferentes, dos mundos unidos (pp. 79-92). Salamanca: Ediciones Universidad Salamanca.

Susini, G. C. (1966). Il lapicida romano. Introduzione all'epigrafia latina. Bologna: Archivio di Stato.

Velázquez Soriano, I. (2008). Los estudios epigráficos. Cuestión de métodos interdisciplinares. Pyrenae, 39(1), 7-41.

Trillmich, W. (1973). Zur Münzpräpung des Caligula von Caesaraugusta (Zaragoza). MDAI(M), 14, 151-173. 